Communications in Physics, Vol. 24, No.3S2 (2014), pp. 83-88

DOI:10.15625/0868-3166/24/3S2/5053

\title{
THE LIGHT-TO-HEAT CONVERSION OF GOLD NANOSHELLS AND NANORODS IN TISSUES
}

\author{
VU THI THUY DUONG, TRINH THI THUONG, NGHIEM THI HA LIEN, DO QUANG HOA \\ AND TRAN HONG NHUNG \\ Institute of Physics, Vietnam Academy of Science and Technology \\ E-mail: vtduong@iop.vast.ac.vn \\ Received 04 April 2014
}

Accepted for publication 24 May 2014

\begin{abstract}
We perform a set of experiments on photo-heating in tissues containing gold nanoshells (NSs) and nanorods (NRs). The temperature of tissues were measured with different amounts gold NSs and NRs under illumination of a continuous diode laser at $808 \mathrm{~nm}$ and power density from 20 to $62 \mathrm{~W} / \mathrm{cm}^{2}$. The temperature of the tissues injected gold nanoparticles increased to $66 \pm 4{ }^{\circ} \mathrm{C}$ for $2.1 \times 10^{8} \mathrm{NSs}$ and $73 \pm 4{ }^{0} \mathrm{C}$ for gold $5.4 \times 10^{9} \mathrm{NRs}$ after 10 min exposition at power density $35 \mathrm{~W} / \mathrm{cm}^{2}$. The control tissue without gold nanoparticles demonstrated a significantly lower temperature $40 \pm 4{ }^{\circ} \mathrm{C}$ in the same time of illumination. The temperature can be reached up to around $100^{\circ} \mathrm{C}$ for tissue with both NSs and $\mathrm{NRs}$ at $62 \mathrm{~W} / \mathrm{cm}^{2}$ inrradiation for $7 \div 10 \mathrm{~min}$.
\end{abstract}

Keywords: gold nanoshells, gold nanorods, photothermal effect.

\section{INTRODUCTION}

Photothermal therapy relies on the principle of converting laser energy into heat leading to tumor necrosis. Simple photothermal therapy performed with not between cancer cells and healthy cells. Besides, high laser power will be needed to sufficiently heat large or deeply embedded tumors. However, by using near-infrared light coupled with thermal agent implanted in the tumor, efficient localized heating can be achieved [1-6].

The photo-heating effect is especially strong for metal nanoparticles (NP) because they have many free electrons. It becomes strongly enhanced under plasmon resonance when the laser frequency hits the collective resonance of the free electrons in NPs. Metal nanoparticles become very useful as agents for photothermal therapy because of their enhanced absorption and scattering cross-sections. The absorption cross-sections of the gold NPs is four to five orders of magnitude larger than those of indocyanine green dye [4]. Additionally, gold NPs manifest a low level of toxicity when introduced into biological systems [3].

Gold nanoshells (NSs) (core silica - shell gold) have generated considerable interest as a photothermal agent due to its absorption cross-sections wavelength selectivity. By controlling the relative thickness of the core and shell layers of the nanoparticles, the plasmon resonance and the absorption band of NSs can be tuned across a broad region of the spectrum from the nearUV to the near-infrared NIR [7-10]. Gold nanorods (NRs) also interested because their optical 
properties are well-matched for exploitation in diagnostic and therapeutic applications. Moreover, the absorption of gold NRs is predicted to be the strongest of all the different shapes of gold and silver nanoparticles $[11,12]$. By changing the aspect ratio between axes of NRs, their absorption and scattering wavelength can be changed from visible to the NIR region. This range the NIR is the region where optical absorption in tissue is minimal.

In this work, we present the reseach results on thermal effects caused by gold NSs and NRs in animal tissue under illumination of a continuous diode laser at $808 \mathrm{~nm}$. The gold NSs and NRs were utilized as thermal agent to efficiently transfer the radiant energy into heat within a localized region. The results demonstrate the ability in increasing also monitoring the temperature of gold NSs and NRs during laser irradiation.

\section{EXPERIMENT}

\section{II.1. Sample preparation}

The gold NSs were synthesized according to previously published procedures [13]. The gold NSs with $140 \pm 10 \mathrm{~nm}$ silica core and $\sim 20 \mathrm{~nm}$ gold shell have the concentration $7 \times 10^{11}$ particles $/ \mathrm{ml}$. The gold NRs were purchased from NanoComposix. The gold NRs with aspects $\sim 41 \times 10 \mathrm{~nm}$ have the concentration $1.8 \times 10^{13}$ particles $/ \mathrm{ml}$.

Chicken tissue samples with size of $4 \times 4 \times 4 \mathrm{~mm}$ were used to study. The solution of gold NSs or NRs was slowly injected into the tissue sample at $2 \mathrm{~mm}$ depth with different nanoparticle amounts. Control tissue samples received the same quantity of water.

\section{II.2. Experimental setup}

The experimental setup for photothermal effect is depicted in Fig. 1A diode laser NIR (808 nm, 2W) was used as light sourse. The laser power was determined by LM-3HTD (Coherent). A optical fiber (Ocean Optics P400-2-UV-VIS), $400 \pm 8 \mu \mathrm{m}$ diameter, open angle tga $=0.2$ is used to guide the laser beam to sample. The temperature of samples was detected with temperature sensor PT100-CRZ. The experiments were performed at room temperature $28^{\circ} \mathrm{C}$.

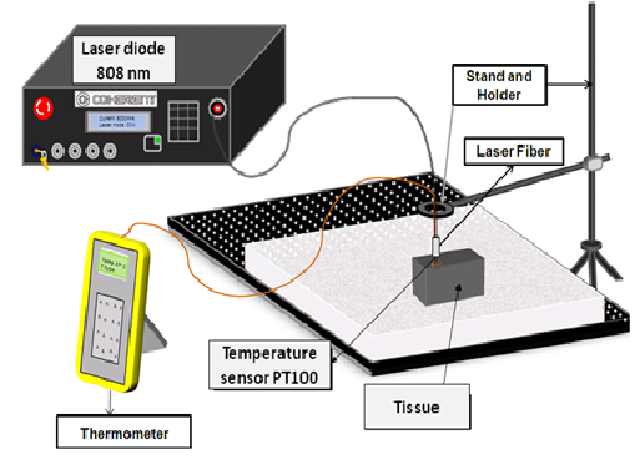

Fig. 1. Experimental setup for measurements of temperature in the tissue.

The morphology of nanoparticles was determined by transmission electron microscopes (TEM, JEM 1011). Absorption spectra were measured using JASCO-V570-UV-Vis-NIR spectrometer. The light scattering images of gold NRs, and NSs were recorded using a Nikon Ti- $E$ microscope and camera DCU223C-CCD (Thorlabs). 


\section{RESULTS AND DISCUSSIONS}

\section{III.1. Characterization of gold nanoparticles}

The gold NSs dispersed in water were synthezied by chemical method described in previous work [13]. The NSs have a spherical silica core $140 \pm 10 \mathrm{~nm}$ coated by a gold shell of about 20 $\mathrm{nm}$ (Fig 2A). The absorption spectra of the NSs solution at room temperature have the plasmon resonance peak around $800 \div 1000 \mathrm{~nm}$ (Fig. 2A). The water-dispersed NRs were purchaged from NanoComposix, having dimensions of length $x$ diameters $=41 \mathrm{~nm} \times 10 \mathrm{~nm}$ (aspect ratio between two axes $\sim 4.0$ ) (Fig. 3A). The plasmon absorption spectra of NRs have two bands: a weak short-wavelength at $515 \mathrm{~nm}$ and a strong long-wavelength at $808 \mathrm{~nm}$, due to the transverse and longitudinal electronic oscillation of NRs, respectively.

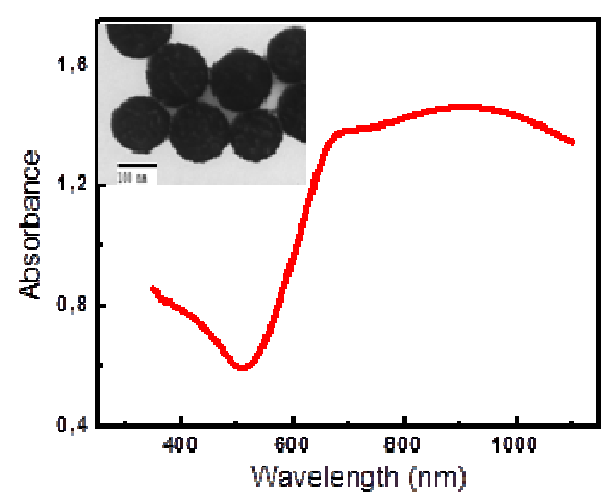

A

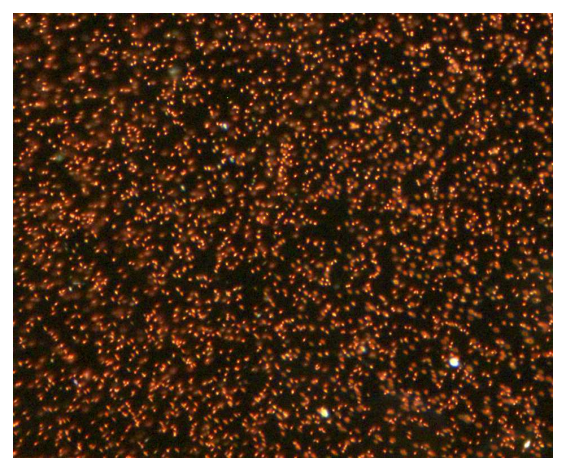

B

Fig. 2. Gold NSs: UV-Vis-NIR spectra and TEM image (inset) (A), Dark-field microscope image, Nikon Ti-E, objective 10X, $\mathrm{Na}=1.3$ (B).

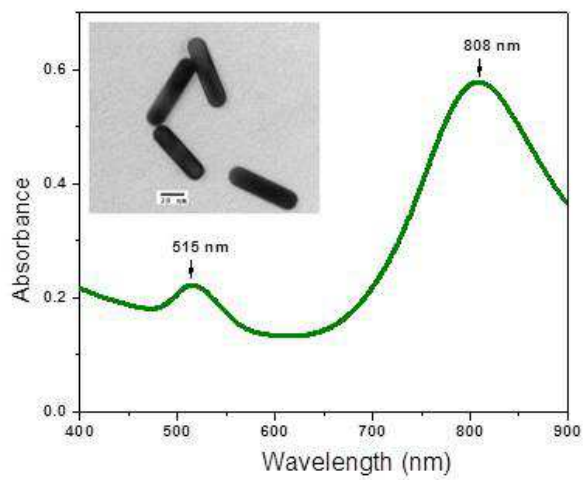

A

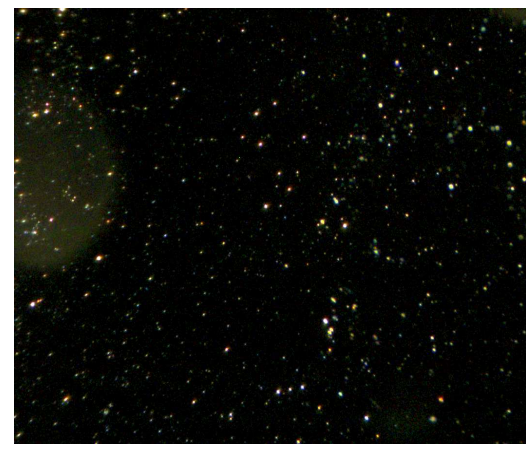

B

Fig. 3. Gold NRs: UV-Vis-NIR spectra and TEM image (inset) (A), Dark-field microscope image, Nikon Ti-E objective 10X, Na=1.3 (B) 
The dark-field microscope images of gold NSs and NRs are presented in Fig. 2B and Fig. 3B, respectively. The nanoparticles scatter different colored light depending on their size and shape. The NSs strongly scatter red light due to the surface plasmon oscillation of gold shells. The NRs shows bright spots with different colors caused by the plasmon resonance scattering axes which are not identical.

\section{III.2. Photothermal properties}

The gold NSs or NRs is are injected into a small cavity inside a massive chicken tissue and become optically stimulated when illuminated by laser light. Fig. 4 shows the time dependence of the temperature change of chicken tissue samples induced by the laser light of power density $62 \mathrm{~W} / \mathrm{cm}^{2}$. Due to the illumination of laser wavelength $808 \mathrm{~nm}$ in the therapeutic window region, the laser light can go through, touch the NPs and excites the surface plasmon resonance. For larger NPs, the scattering feature becomes greater. The scattered light energy contributes to the heating process of the surrounding environment, leading to and increase in temperature of the samples. The tissue reaches the steady-state temperature after 20 minutes of excitation. The temperature can be reached to around $100{ }^{\circ} \mathrm{C}$ after illumination for $7 \div 10 \mathrm{~min}$. While the laser light is turning off, the temperature of samples decreases rapi-

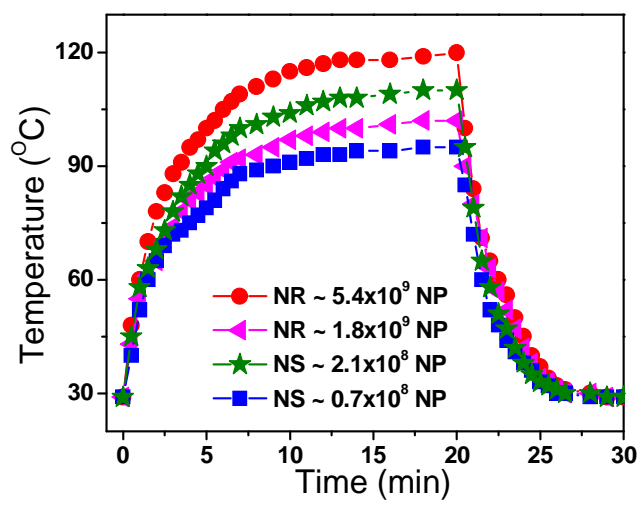

Fig. 4. Temperature variations of chicken tissue samples injected with gold NS and gold NR solutions under the illumination of the laser light at power density $62 \mathrm{~W} / \mathrm{cm}^{2}$ as function of time. delly from the maximum to the room. The results are shown in Table 1.

Table 1. Temperature of tissue injected with NPs after 20 min expossition under laser light at power density $62 \mathrm{~W} / \mathrm{cm}^{2}$.

\begin{tabular}{|l|c|c|}
\hline \multirow{2}{*}{ NP } & Number of NP & Temperature $\left({ }^{\circ} \mathrm{C}\right)$ \\
\hline \multirow{2}{*}{ Gold nanoshells } & $0.7 \times 10^{8}$ & 95 \\
\cline { 2 - 3 } & $2.1 \times 10^{8}$ & 110 \\
\hline \multirow{2}{*}{ Gold nanorods } & $1.8 \times 10^{9}$ & 102 \\
\cline { 2 - 3 } & $5.4 \times 10^{9}$ & 120 \\
\hline
\end{tabular}

Each individual nanoparticle can be considered as an independent heat source. The localized increase of the temperature around a single nanoparticle depends upon the absorption cross section, laser intensity, morphology of the nanoparticle, and thermal conductivities of both the metal and surrounding medium [14]. The temperature increase on the surface of an individual 
nanoparticle in medium is shown by the equation:

$$
\Delta T_{N P}=\frac{\sigma_{a b s} \cdot I}{4 \pi R_{e q} \beta k_{0}}
$$

where $\sigma_{a b s}$ is absorption cross section $\left(\mathrm{m}^{2}\right) ; I$ is power density of the incident light $\left(\mathrm{W} / \mathrm{m}^{2}\right) ; R_{e q}$ is equivalent radius of a sphere with the same volume as the particle $\left(R_{e q}=\left(\frac{3 V_{N P}}{4 \pi}\right)^{1 / 3}, \mathrm{~m}\right) ; \mathrm{k}_{0}$ is thermal conductivity of the surrounding medium; and $\beta$ is thermal capacity coefficient dependent on nanoparticle aspect ratio (ar): $\beta=1$ for NSs or spheres, $\beta=1+0.96586\left(\ln ^{2}(a r)\right)$ for rods [14]. We can see that the temperature increase at the surface of a single NP is really very small. The overall increase of temperature is due to a collective heating effect of many nanoparticles. In other words, the average increase of temperature in the samples $(\Delta \mathrm{T})$ is generated by amounts of NP and illumination density.
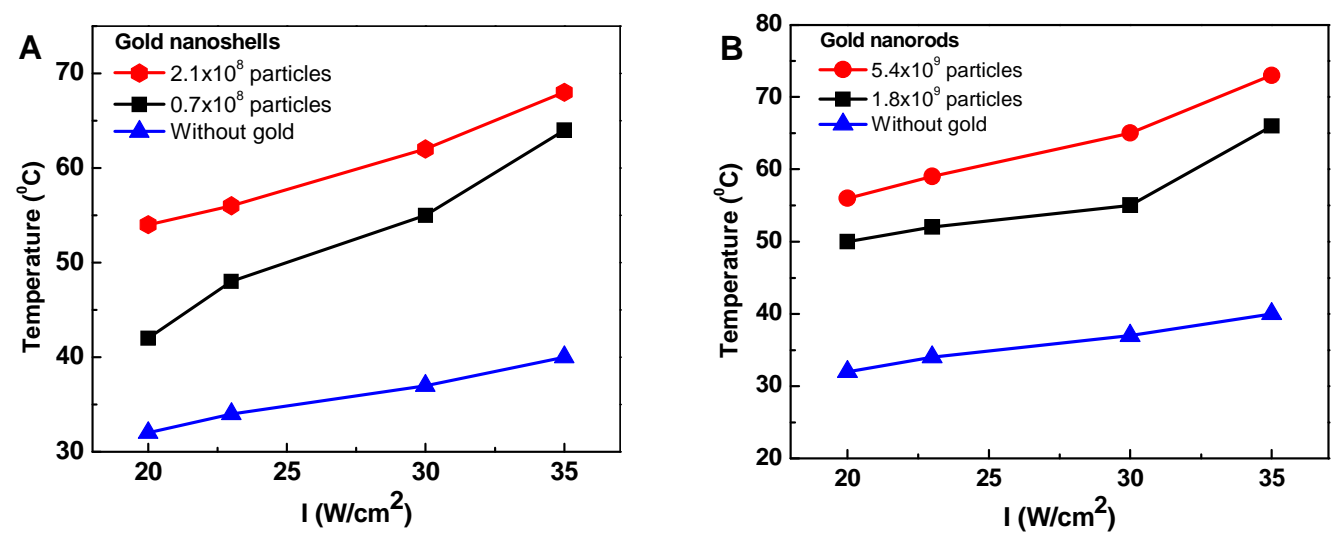

Fig. 5. Temperature of tissue samples injected with different amounts of gold NSs and NRs as function of illumination power density $\mathrm{I}\left(\mathrm{W} / \mathrm{cm}^{2}\right)$.

Fig. 5 shows the temperature variations of tissue samples injected with different amounts of gold NSs or gold NRs versus laser power density for $10 \mathrm{~min}$ of illumination. The results show that the temperature of samples reach to $62 \pm 4^{\circ} \mathrm{C}$ and $66 \pm 4^{\circ} \mathrm{C}$ with NS amount of $0.7 \times 10^{8}$ particles and $2.1 \times 10^{8}$ particles, respectively, at power density $35 \mathrm{~W} / \mathrm{cm}^{2}$ (Fig. $5 \mathrm{~A}$ ). While, the temperature in the control injected water tissues slowly increased and reached a steady level of $40 \pm 4^{\circ} \mathrm{C}$. The temperature difference in the presence and absence of NSs is around $10 \div 22^{\circ} \mathrm{C}$ for power density $20 \mathrm{~W} / \mathrm{cm}^{2}$ and $24 \div 28^{\circ} \mathrm{C}$ for power density $35 \mathrm{~W} / \mathrm{cm}^{2}$. For NR injected tissues, the temperature of samples increases to $66 \pm 4^{\circ} \mathrm{C}$ and $73 \pm 4^{\circ} \mathrm{C}$ for $1.8 \times 10^{9}$ particles and $5.4 \times 10^{9}$ particles, respectively, at power density $35 \mathrm{~W} / \mathrm{cm}^{2}$ (Fig. 4B). The temperature difference in the presence and absence of NRs is around $18 \div 24{ }^{0} \mathrm{C}$ for power density $20 \mathrm{~W} / \mathrm{cm}^{2}$ and $26 \div 32^{\circ} \mathrm{C}$ for power density $35 \mathrm{~W} / \mathrm{cm}^{2}$. This temperature can induce the irreversible damage to tissue. From these results, we can see that the maximum temperature of samples is proportional with the illuminate power density and NPs amount. The tissues need to be injected a NR amount of $1.8 \times 10^{9}$ particles to reach $66 \pm 4{ }^{\circ} \mathrm{C}$ at power density $35 \mathrm{~W} / \mathrm{cm}^{2}$, while they need only $2.1 \times 10^{8} \mathrm{NS}$ particles to reach the same temperature. 


\section{CONCLUSION}

The temperature of tissues were measured with different amounts gold NSs and NRs, power density from 20 to $62 \mathrm{~W} / \mathrm{cm}^{2}$ after laser excitation at $808 \mathrm{~nm}$ for $20 \mathrm{~min}$. The results show that the temperature of samples reach to $62 \pm 4^{\circ} \mathrm{C}$ and $66 \pm 4^{\circ} \mathrm{C}$ with $\mathrm{NS}$ amount of $0.7 \times 10^{8}$ particles and $2.1 \times 10^{8}$ particles, respectively, at power density $35 \mathrm{~W} / \mathrm{cm}^{2}$. The tissues need to be injected a NR amount of $1.8 \times 10^{9}$ particles to reach $66 \pm 4^{\circ} \mathrm{C}$ at power density $35 \mathrm{~W} / \mathrm{cm}^{2}$, while they need only $2.1 \times 10^{8} \mathrm{NS}$ particles to reach the same temperature. The temperature can be reached to about $100^{\circ} \mathrm{C}$ when using nanoparticles and exposuring at power density $62 \mathrm{~W} / \mathrm{cm}^{2}$ for $7 \div 10 \mathrm{~min}$.

\section{ACKNOWLEGMENT}

This work was supported by Young Researches project No. VAST.LT.12/14-15 and National project No. 1/2/2011/HD-NCCBUD.

\section{REFERENCES}

[1] L. R. Hirsch, R. J. Stafford, J. A. Bankson, S. R. Sershen, B. Rivera, R. E. Price, J. D. Hazle, N. J. Halas and J. L. West, PNAS. 23 (2003) 13549.

[2] X. Huang, P. K. Jain, I. H. El-Sayed, M. A. El-Sayed, Lasers Med. Sci. 23 (2008) 217.

[3] E. E. Connor, J. Mwamuka, A. Gole, C. J. Murphy, M.?D. Wyatt, Small 1 (2005) 325.

[4] M. L. J. Landsman, G. Kwant, G. A. Mook, W. G. Zijlstra, J. Appl. Physiol. 40 (1976) 575.

[5] D. Pissuwan, S. M. Valenzuela and M. B. Cortie, Biotechnology and Genetic Engineering Reviews 25 (2008) 93.

[6] V. P. Zharov, V. Galitovsky, M. Viegas, Appl. Phys. Lett. 83 (2003) 4897.

[7] K. Sokolov, M. Follen, J. Aaron, I. Pavlova, A. Malpica, R. Lotan, and R. R. Kortum, Cancer Res. 63 (2003) 1999.

[8] B. L. Tong, Y.Zhao, T. B. Huff, M. N. Hansen, A. Wei, J. X. Cheng, Adv. Mater. 19 (2007) 3136.

[9] J. Shah, S. R. Aglyamov, K. Sokolov, T. E. Milner, S. Y. Emelianov, Optics Express 16 (2008) 3776.

[10] A. O. Govorov and H. H. Richardson, Nanotoday 2 (2007) 30.

[11] D. B. Chithrani, M. Dunne, J. Stewart, C. Allen, D. A. Jaffray, ScienceDirect 6 (2010) 161.

[12] M. P. Melancon, W. Lu, M. Zhong, M. Zhou, G. Liang, A. M. Elliott, J. D. Hazle, J. N. Myers, C. Li, R. J. Stafford, Biomaterials 32 (2011) 7600.

[13] Thi Ha Lien Nghiem, Tuyet Ngan Le, Thi Hue Do, Thi Thuy Duong Vu, Quang Hoa Do, Hong Nhung Tran, $J$. Nanopart Res, Springer 15 (2013) 2091.

[14] G. Baffou, R. Quidant, and F. Javier Garcıa de Abajo, ACS NANO 2 (2010) 709. 